\title{
The Diagnostic Challenges, Possible Etiologies and Lack of Researches of Hepatocellular Carcinoma in Somalia
}

\author{
Mohamed Abdulkadir Hassan-Kadle ${ }^{1,2,3}$ \\ ${ }^{1}$ Dufle Specialist Hospital, Mogadishu, Somalia \\ ${ }^{2}$ Abrar Research and Training Centre, Abrar University, Mogadishu, Somalia \\ ${ }^{3}$ Peoples' Friendship University of Russia (RUDN University), Moscow, Russia \\ Email: kadlesom@gmail.com
}

How to cite this paper: Hassan-Kadle, M.A. (2017) The Diagnostic Challenges, Possible Etiologies and Lack of Researches of Hepatocellular Carcinoma in Somalia. Open Journal of Gastroenterology, 7, 115123.

https://doi.org/10.4236/ojgas.2017.73013

Received: January 27, 2017

Accepted: March 28, 2017

Published: March 31, 2017

Copyright $\odot 2017$ by author and Scientific Research Publishing Inc. This work is licensed under the Creative Commons Attribution International License (CC BY 4.0).

http://creativecommons.org/licenses/by/4.0/

\begin{abstract}
Globally, hepatocellular carcinoma is the second amongst all causes of cancer deaths and it is one of the common malignancies in both developing and developed countries. The causes are variety all of the world ranging from geography, life style and advanced medical care that is available in those countries either developing such as Somalia or developed countries. Somali contributes to global burden of hepatitis B which is a known risk factor for HCC and has categorized to the world a part of high prevalence of hepatitis $B$ which is greater than $10 \%$, while there is no more available data of hepatitis $\mathrm{C}$ in Somalia that contributes the world. Diagnoses of hepatocellular carcinoma are now forward in many countries of developed world, but reality are different from developing countries such as Somalia which is now out for civil war and has a lack of medical experts in all fields of medicine such as physician, surgeons, pathologists, radiologists and the experts of the laboratory field, even if we have these medical personal who are few or they are elder than above 60 years old plus medical equipment (such as imaging and laboratory equipment). All these challenges, the author of this manuscript has faith in the diagnosis of hepatocellular carcinoma that can be rationally made to consider the clinical presentation of this disorder and to maximize use of offered diagnostic tools and to refer the few medical experts in the country.
\end{abstract}

\section{Keywords}

Diagnostic Challenges, Hepatocellular Carcinoma, Somalia

\section{Introduction}

Cancer results in among 14 million new cases and 8 million deaths worldwide 
per annum in 2012 affecting populations in all of countries and all regions. The most common causes of cancer according to IARC include Lung (1.59 million deaths), Liver (745,000 deaths), Stomach (723,000 deaths), Colorectal (694,000 deaths), Breast (521,000 deaths), Esophageal cancer (400,000 deaths). Hepatocellular carcinoma (HCC) is the fifth most common cancer with more than 750,000 new cases occurring in the worldwide each year, between gender; men was the most prevalent than women 554,000 and 228,000 respectively. HCC is the second most common cause of cancer death in the world with 745,000 deaths in the year 2012. Eighty percent of global HCC occurs in developing countries and HCC is one of the three most common tumors in these counties. Eastern and south-eastern Asia and almost of sub-Saharan Africa are low income regions with high incidences of the tumor. In 2013 World Health Organization (WHO) launched "Global Action Plan for Prevention and Control of Non-communicable Disease 2013-2020". The main objective of this plan is to reduce premature mortality due to cancer, cardiovascular and chronic respiratory disease, and diabetes by $25 \%$ of the year 2025 [1]

In our knowledge, we well knew risk factors for HCC including infections (chronic hepatitis B and hepatitis C), dietary exposure to the fungal toxin (aflatoxin), tobacco, immunologic (autoimmune hepatitis, primary biliary cirrhosis) alcohol consumption, genetic (hereditary hemochromatosis, tyrosinosis), alpha 1 antitrypsin deficiency and Wilson disease. The most common cause of HCC are chronic hepatitis B and C infections, almost $80 \%$ of global HCC [2], but there is a difference in worldwide about these two infections according to geographical distribution and the age pattern. In developed countries, the commonest cause is related to alcohol hepatitis due to alcohol consumption and hepatitis $C$ virus infection due to intravenous drug injection that are all related to older ages, although in developing countries, the commonest cause is hepatitis B virus which is mainly transmitted through vertically, but horizontal transmission are less transmitted than vertical transmission and aflatoxin which is related to the early exposure. Hepatitis B virus is preventable infection but there is a lack of hepatitis B vaccine coverage in the developing countries in the past especially in sub-Saharan Africa, while horizontal transmission of hepatitis B is also rising in developing countries among children due to salivary viral shedding while playing each other and the incomplete of sterilization of barbers is also another reason among adults in the developing countries and its partially describes the high of hepatitis B related to HCC in the developing countries [3].

In Somalia, the etiologies of HCC are not different in our region and rest overall the world, although hepatitis B virus has been grouped as part of areas of the world where the HBV infection with prevalence $>10 \%$ is demonstrated in Figure 1 , while hepatitis $C$ virus is not unavailable data known prevalence in the country as presented in Figure 2, few articles were reported prevalence of hepatitis C virus that not contributed the world but in other hand there are other causes of HCC rather than viral hepatitis which are now increasing such as storage of food in the ground (aflatoxin), poor quality of food and expired food, all these factors have an important role in playing during and after civil war due to lack of 


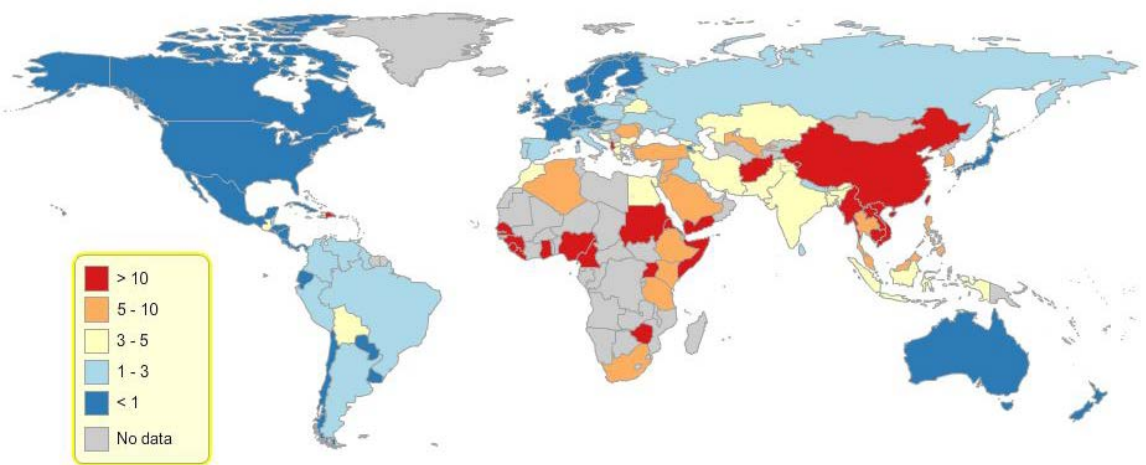

Figure 1. Hepatitis B prevalence worldwide. Source: Center for disease analysis.

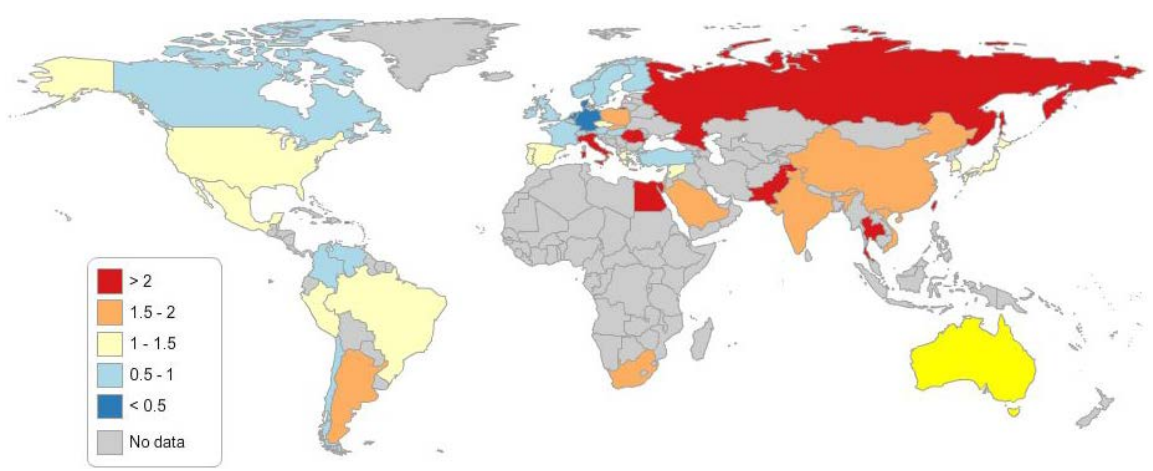

Figure 2. Worldwide prevalence of hepatitis C. Source: Center for disease analysis.

quality control until now. There are three studies about viral hepatitis B and C among patients with hepatocellular carcinoma that conducted before and after civil war; one study about chronic liver disease including HCC before civil war and after civil war that is not yet published and another study in immigrant Somali community in Minnesota, these few studies are not still enough for prevalence of the country of hepatocellular carcinoma, so we need future more research about HCC and their etiologies and in all regions of the country.

\section{Possible Etiologies in Somalia}

In our outlook of possible etiologies we do not have an exactly cause of HCC that presents in background of cirrhosis in the worldwide accounting 80\%-90\% [3], so we want to know what are the causes of cirrhosis which is proven in literally that any cause of cirrhosis (Chronic Hepatitis B and C, Aflatoxins, Non-alcoholic liver disease, alcohol hereditary hemochromatosis and autoimmune hepatitis) can lead to HCC. There are some studies that were done before and after civil war, but it is still not enough to get exactly prevalence of cirrhosis and HCC, so we need a research to find out between the etiologies and cirrhosis/ HCC.

Study that was conducted before civil war; Bile K et al. published in 1993 about chronic liver disease including HCC was a result of 37.1\% (23/62) subjects had positive with HBsAg, while in HCV were showed 40.3 (25/62) to antibody of HCV positive [4]. After civil war there are two studies one is conducted locally while the other one conducted to Somali immigrant community in Minnesota; 
the study that conducted locally is about HCC that is not yet published in peer review journals and it's demonstrated a result of that HBsAg is higher than HCV with $39.10 \%$ and $19.2 \%$ respectively [5]. While Minnesota study showed difference from one local study and the other one was similar, and it presented a result of $17.9 \%$ among HCC subjects had HBsAg positive while antibody to HCV showed a result of $75.9 \%$ among patients with HCC [6].

In our clinical experiences; Somalia the etiologies such as the prevalence of hepatitis B and C of HCC was much higher previous than later due to the lack vaccination for hepatitis $B$ in the previous children due to civil war and lack of government that plans for preparation of this vaccine to add in Expanded Programme on Immunization and awareness program which is very low in the past and now, while the mass in the right hypochondrium is much higher last three decades, so there are an area of calling to do research in country-wide with an urgent study to determine the prevalence of possible etiologies such as hepatitis $\mathrm{B}$ and C of liver cirrhosis/HCC and prevalence of cirrhosis and HCC in Somalia, and we also remain the other possible etiologies rather than hepatitis $B$ and $C$ in Somalia which are now increasing in our clinical experience such as storage of food on the ground, poor quality of food, sedentary life style, obesity and diabetes, all these factors they have an important role to play and to do a research that does not done still before and after civil war.

\section{Incidence and Mortality}

Globally; especially in Africa and Asia there are approximately at $85 \%$ of global liver cancer. So the areas where the incidence of liver cancer greater than 20 per 100,000 population and this include sub-Saharan Africa, eastern Africa and in contrast the developed counties such as Europe and North America are low incidence than the our region with incidence of HCC greater than 10 per 100,000 population [1]. In our outlook the HCC associated the gender, age standardized rate and the incidence rate we did not have any available data, but there is one study done after civil war that showed male predominance [5] and that study is hospital-based data and it doesn't reflect a true population base prevalence of HCC in recent years.

\section{Clinical Features}

Patients generally present with symptoms of advancing cirrhosis, as you know $80 \%-90 \%$ of HCC is a background of cirrhosis [2] and these symptoms are mimics symptoms of cirrhosis and it includes pruritus, jaundice, splenomegaly, cachexia, hepatomegaly, variceal bleeding (Hematemesis/Melena) right upper quadrant pain, ascites, hepatic encephalopathy, periumbilical collateral veins, asterixis. While the ultrasound was incidentally finding with unrelated complains. In our country, patients came to the hospitals at the end stage of liver disease with more advanced symptoms due to uninterested to go to physicians when they become sick due to their poor socio-economic condition, life style as well as lack of awareness of the disease. 


\section{Screening, Diagnosis of HCC and Diagnostic Challenges in Somalia}

For diagnosing of HCC remains controversial in all over the world, particularly true lesions less than $1 \mathrm{~cm}$ in size but for the lesions greater than $1 \mathrm{~cm}$ in size were typically showing CT and MRI for establishing the diagnosis of hepatocellular carcinoma. Ultrasound can also detect the liver tumors as small as 1.6 plus or minus $0.6 \mathrm{~cm}$ and it has very sensitive and specific that greater than $90 \%$ but it depends on expert sonographer [7]. Ultrasound and serum alpha fetoprotein are good for screening of HCC according to European association on study of liver-European organization for research and treatment of cancer (EASLEORTC) it recommends against the use of alpha fetoprotein for regular screening given due to its low specificity and additional cost per primary liver cancer detected (\$1982 (US alone) versus \$3639 (AFP + US)) [8] [9] [10] [11]. Other diagnosis tests for jaundice or liver mass of unknown cause are the routine investigations such as Complete blood count, Urea, and Electrolytes, Liver function tests and coagulations; these test offer a clue of possible etiologies or status such as in raised MCV, white blood cells, thrombocytopenia, urea and creatinine, gamma glutamyl transferase, deranged coagulation, a very high of AST and ALT, low platelets and high INR we suspected all these alcohol, infection and leukaemia and portal hypertension, hepatorenal syndrome, HCC, ischemic liver or paracetomol overdose and you reconsider a liver biopsy respectively. In non-invasive liver screening tests such as autoimmune hepatitis (immunoglobulin $\mathrm{G}, \mathrm{A}$ and $\mathrm{M}$ ) and liver autoantibodies such as AMA, Gastric parietal cell, LKM antibody and smooth muscle antibody, for Wilson disease (copper and serum ceruloplasmin), for deficiency of alpha 1 antitrypsin (alpha 1 antitrypsin level) for acute and chronic hepatitis (hepatitis $B$ and $C$ ) while in acute jaundice (Hepatitis A, CMV, EBV, and Adenovirus) for hereditary hemochromatosis (serum ferritin level) and for non-alcoholic liver disease (serum lipids). However the definitive diagnosis of HCC is histological that takes liver biopsy through US guided liver intervention or blind intervention although US guided is safer than blind intervention. In our country we did not have a screening program or guideline about screening and well diagnostic equipment, such as tests of AFP tumor maker that is good to detect if there is liver cancer and in our private hospitals they did not had this test or may be one or few hospitals have this test but it's not more considered, in terms of ultrasound equipment, the country has more equipments of ultrasound even in every region but there is a very low sonographer experts and low practice for detecting such that tumors even if its larger tumors for sonographers. In CT-Scan and MRI are not same to the ultrasound but few regions in the country had these diagnostics; but there is no medical experts in the country only the experts are foreign experts, so in our country we are a very limited investigation of HCC and its possible etiologies and a lack of medical expertise in all fields such as medical laboratory technician, medical imaging technician and very low clinicians in all fields of medical subjects all 
these due to civil war of the country. In terms the non-invasive tests of liver are same as pervious tests and imaging although such tests like liver function tests and rapid tests for viral hepatitis are available in most of centers of the country but in viral load tests, autoimmune hepatitis tests, Wilson disease tests, genetic tests and their equipment's (ELISA, PCR real time) are now unavailable in the country. Even we have few pathologists not more than three to five in the country even if we think to take a liver biopsy, we did not have more experts taking a liver biopsy through ultrasound guided or blind intervention. All these are limited resources to make the diagnosis of HCC hard and to determine the possible etiologies of the HCC and also we did not have a society working for studying liver disease that makes guidelines for recommendations such as (diagnosing, screening and management guidelines, awareness programs and studying liver disease) and this the reality at this period for writing and publishing of this article. So the author imply US, AFP, LFTs, viral hepatitis serology with good medical equipment's and medical expertise and good clinical approach should pick up most of HCC cases and determine their possible etiologies that are important in our country (viral hepatitis).

\section{Global Research on HCC Including Somalia}

Worldwide, the research programs on HCC pauses for certain other cancers such as breast cancer, but the major contributor for HCC research is China rather than other countries of the world including USA, UK for last 5 years using PubMed are 6408, 1803, and 258 publications of observational studies and clinical trials respectively. While in our region such as Sudan, Kenya, Ethiopia, Uganda, are 13, 9, 5, 4 publications of observational studies respectively from 1975 to 2016 and in our country 2 publications and one unpublished articles from 1985 to 2016 before and after the war and this retrieved from PubMed on 31 May 2016.

\section{Treatments}

The definitive curative treatments for hepatocellular carcinoma are hepatic resection or liver transplantation, these two treatments of HCC are depends the tumor characteristics such as the size, nodularity spread (metastasis) and vascular invasion, underlying liver function and performance status of ECOG (Eastern Cooperative Oncology Group performance status) and all these factors plays an important role for patient survival [12]. The most system of staging liver cancer is Barcelona Clinic Cancer (BCLC) which is combined the characteristics of tumor, liver function and patient performance status for allocation to different stages as show in Figure 3, although globally not yet accepted this staging system but it appear the most prognostic information. According to the survival, HCC has a poor prognosis in both developed and developing countries, although developing countries are worse than developed country, and mortality is roughly equivalent to incidence rates. For international Agency for Research on 


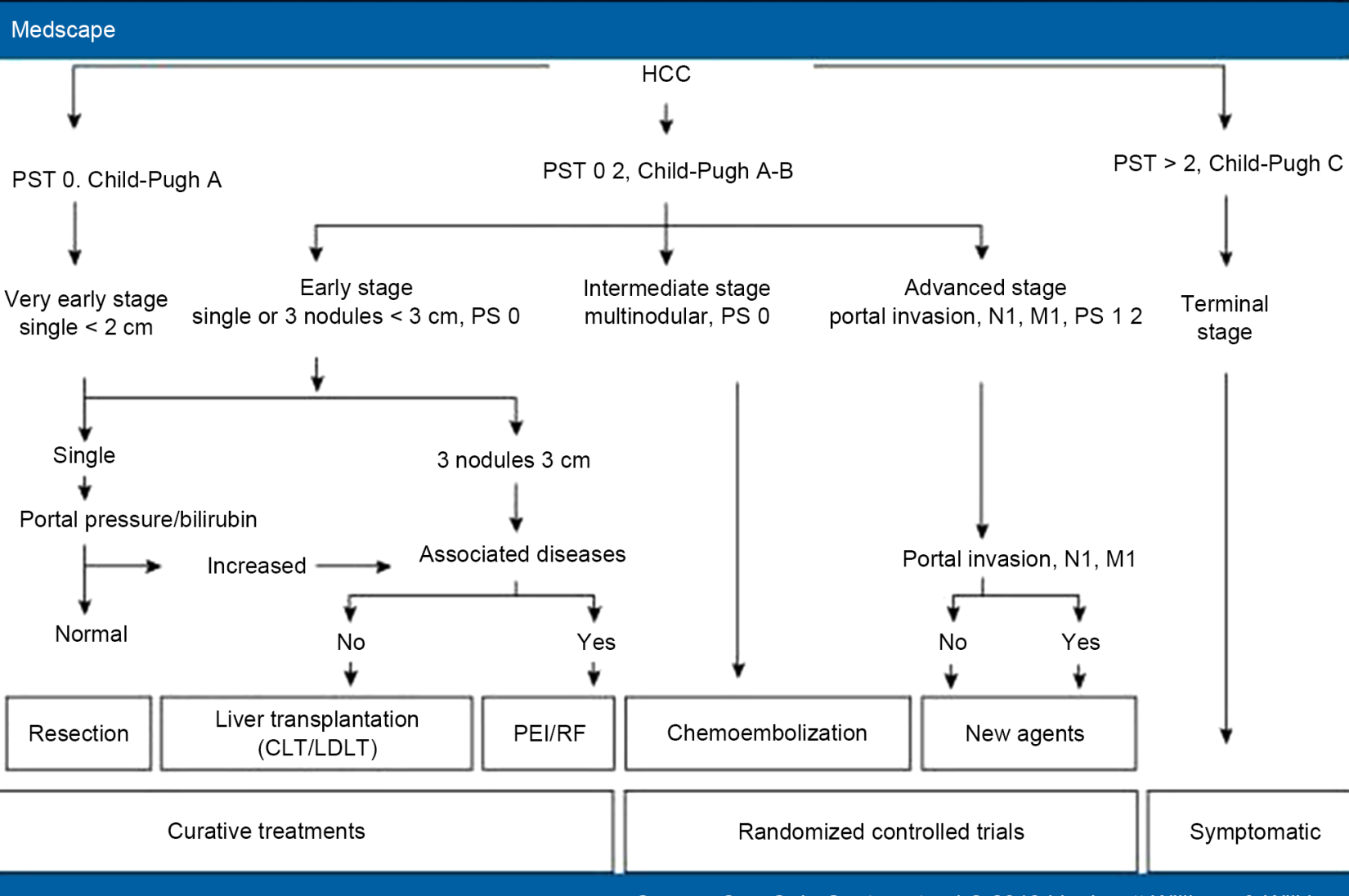

Source: Curr Opin Gastroentercl @ 2010 Lippincott Williams \& Wilkins

Figure 3. Treatment algorithm for patients with hepatocellular carcinoma using the barcelona clinic liver cancer staging system.

Cancer (IARC) the incidence mortality ration of HCC was 0.95 and geographically patterns of incidence to mortality are nearly uniform according to statistics 2015 of IARC [13].

In our outlook, most of patients came to the hospital to advanced stage or end of the liver disease and they didn't receive a definitive treatment of HCC due to the unavailable of these treatment in our setup and there is no specialist center for liver disease for these treatment of HCC before and after civil war, but the patients received a supportive treatment both early stage and advanced stage due to the limited recourses of the county, so missing of specialist center in the country majority of our patients being treated by physician alone. The issue of travel in foreign countries is difficult to most of our population to receive a medical care and well equipments for diagnosis and treatment.

\section{Conclusion}

The possible etiologies, difficult diagnosis and the prevalence of HCC clearly indicate the high risk of HCC in Somalia. So we concluded from my recommendation is to maximize our clinical senses in finding a detailed history taking, examination with complementing our limited investigations that are available in our country. Well diagnostic center such as imaging studies, laboratory (surveillance), awareness of the possible causes such as hepatitis B and C, aflatoxin to 
the population through media or any sources (Prevention), and appropriate treatment can significantly improve the outcome and decrease incidence of HCC in Somalia. The author also imply doing a research that definitely is need in this field to determine the common causes of HCC in Somalia and their dispersion region-wide or nation-wide.

\section{Acknowledgements}

I wish to acknowledge Abrar Research and Training Centre, Abrar University for their financial support to publish this manuscript. I also thank my father and brothers for their encouragement, especially Dr. Ahmed Abdulkadir H. Kadle.

\section{References}

[1] International Agency for Research on Cancer (2014) World Cancer Report 2014. IARC, Lyon.

[2] Perz, J.F., Armstrong, G.L., Farrington, L.A., et al. (2006) The Contributions of Hepatitis B Virus and Hepatitis C Virus Infections to Cirrhosis and Primary Liver Cancer Worldwide. Journal of Hepatology, 45, 529-538. https://doi.org/10.1016/j.jhep.2006.05.013

[3] Mittal, S. and El-Serag, H.B. (2013) Epidemiology of Hepatocellular Carcinoma: Consider the Population. Journal of Clinical Gastroenterology, 47, S2-S6.

[4] Khalif, B., Cadigia, A., Heléne, N., Lars, M., Greger, L. and Lars, N. (1993) Important Role of Hepatitis C Virus Infection as a Cause of Chronic Liver Disease in Somalia. Scandinavian Journal of Infectious Diseases, 25, 559-564. https://doi.org/10.3109/00365549309008543

[5] Shire, A.M., Sandhu, D.S., Kaiya, J.K., Oseini, A.M., Yang, J.D., et al. (2012) Viral Hepatitis among Somali Immigrants in Minnesota: Association of Hepatitis C with Hepatocellular Carcinoma. Mayo Clinic Proceedings, 87, 17-24. https://doi.org/10.1016/j.mayocp.2011.08.001

[6] Kadle, M., Hassan, A.M., Yasin, A.M., Sheikh, A.H., Omar, M.Sh. and Sayid, A.M. (2012) Frequency of Hepatocellular Carcinoma and Its Associated of Hepatitis B and $\mathrm{C}$ in Patients Attending Mogadishu Hospitals.

https://www.researchgate.net/publication/309564485_Frequency_of_Hepatocellular _Carcinoma_and_its_associated_Hepatitis_B_and_C_in_Patients_attending_Moga dishu_hospitals

[7] National Comprehensive Cancer Network (2013) NCCN Clinical Practice Guidelines in Oncology: Hepatobiliary Cancers. National Comprehensive Cancer Network, Fort Washington.

[8] European Association for the Study of the Liver and European Organisation for Research and Treatment of Cancer (2012) EASLEORTC Clinical Practice Guidelines: Management of Hepatocellular Carcinoma. Journal of Hepatology, 56, 908 943. https://doi.org/10.1016/j.jhep.2011.12.001

[9] Villanueva, A., Minguez, B., Forner, A., Reig, M. and Llovet, J.M. (2010) Hepatocellular Carcinoma: Novel Molecular Approaches for Diagnosis, Prognosis, and Therapy. Annual Review of Medicine, 61, 317-328. https://doi.org/10.1146/annurev.med.080608.100623

[10] Hoshida, Y., Nijman, S.M.B., Kobayashi, M., et al. (2009) Integrative Transcriptome Analysis Reveals Common Molecular Subclasses of Human Hepatocellular Carcinoma. Cancer Research, 69, 7385-7392. https://doi.org/10.1158/0008-5472.CAN-09-1089 
[11] Zhang, B. and Yang, B. (1999) Combined Alpha Fetoprotein Testing and Ultrasonography as a Screening Test for Primary Liver Cancer. Journal of Medical Screening, 6, 108-110. https://doi.org/10.1136/jms.6.2.108

[12] Oken, M.M., Creech, R.H., Tormey, D.C., Horton, J., Davis, T.E., McFadden, E.T. and Carbone, P.P. (1982) Toxicity and Response Criteria of the Eastern Cooperative Oncology Group. http://www.npcrc.org/files/news/ECOG_performance_status.pdf

[13] Singal A.G. and Marrero, J.A. (2010) Recent Advances in the Treatment of Hepatocellular Carcinoma Curr Opin Gastroenterol.

http://www.medscape.com/viewarticle/720694_3

Submit or recommend next manuscript to SCIRP and we will provide best service for you:

Accepting pre-submission inquiries through Email, Facebook, LinkedIn, Twitter, etc. A wide selection of journals (inclusive of 9 subjects, more than 200 journals)

Providing 24-hour high-quality service

User-friendly online submission system

Fair and swift peer-review system

Efficient typesetting and proofreading procedure

Display of the result of downloads and visits, as well as the number of cited articles Maximum dissemination of your research work

Submit your manuscript at: http://papersubmission.scirp.org/

Or contact ojgas@scirp.org 